\title{
Crisis Open Christmas - a volunteer's reflection
}

Please send any ideas for feature articles for consideration to:

Rowena Milan,

British Dental Journal,

The Macmillan Building,

4-6 Crinan Street,

London

N1 9XW

Email:r.milan@nature.com

Every year, some of London's dentists volunteer their services to provide dental care to the homeless over the Christmas period. Here, Simon Cheng gives a short account of his experiences as a volunteer for Crisis Open Christmas.

Christmas for most is a period for celebration, rest, warmth, food, and family gatherings. However, for London's homeless this is certainly not the case. Crisis Open Christmas (COC) provides warmth and companionship at a time when loneliness and isolation can be particularly acute. It can also help to bring some compassion and hope into lives of some of the most vulnerable and marginalised people in London today.

Being a volunteer for the first time evoked a series of emotions and responses, including happiness, sadness, elation, compassion, and even a bit of apprehension (even though I have been a dentist for seventeen years). But providing dental care was just a small fraction of all the other services and activities available for the homeless (our guests) at COC.

Dental care was provided in three mobile dental units (MDUs) which were vehicles specially converted for dentistry. These MDUs were parked outside the main access centre and manned by three dental teams.

Each dental team consisted of four dental volunteers: the dentist, two DSAs, and a 'runner' whose job it was to escort our patients/guests to and from the MDUs. In fact most members of the teams were dentists, and of course throughout the day the jobs were rotated. An amusing observation was that some dentists were more apprehensive about the role of the DSA than actually treating the guests.

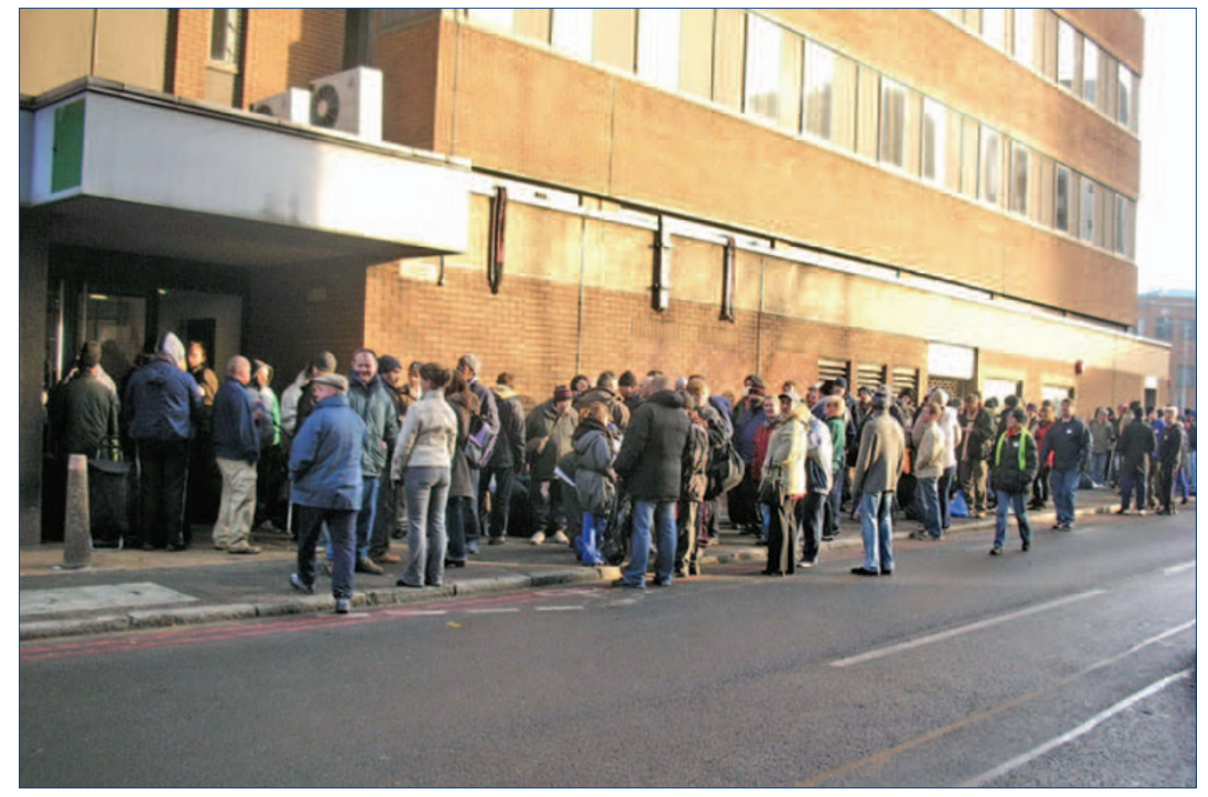

Guests queuing up at the access centre

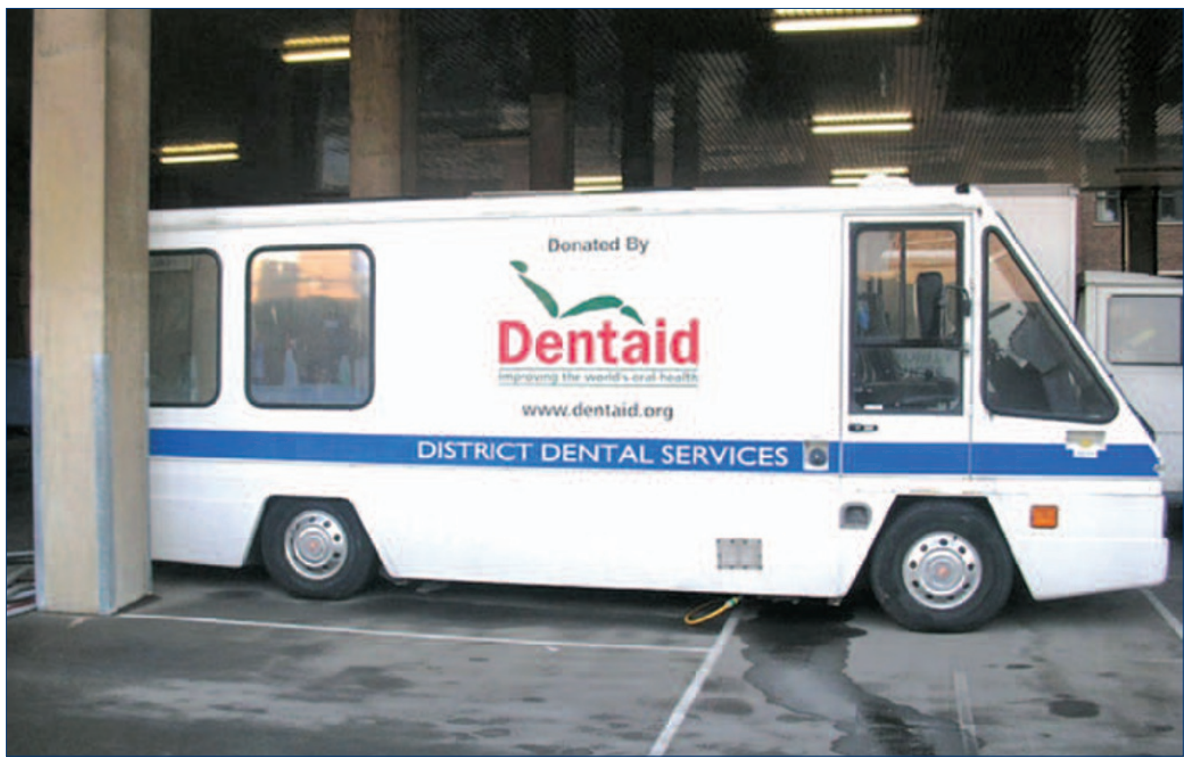

One of the three mobile dental units donated by Dentaid 


\section{FEATURE}

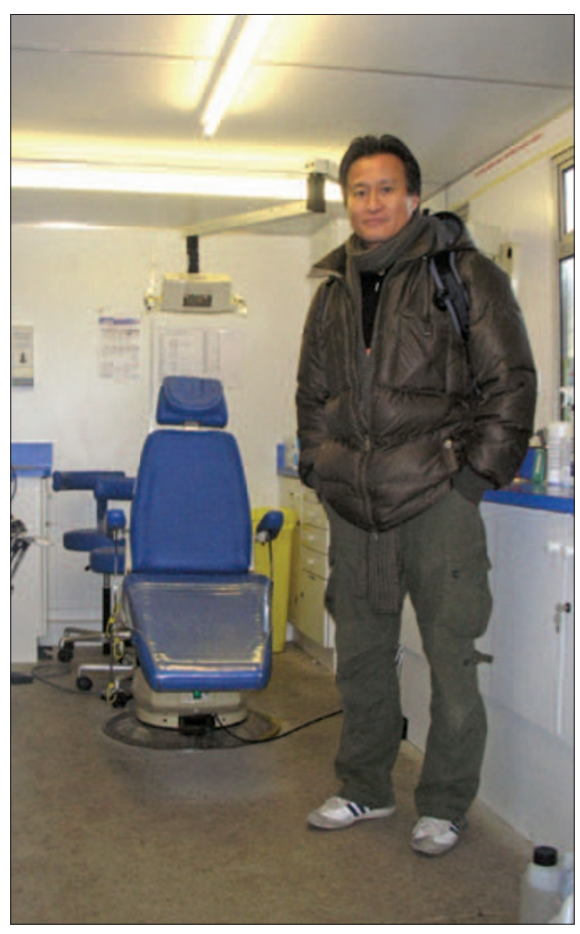

Inside the unit
The equipment and materials were sourced and donated with the help of the British Dental Trade Association (BDTA) and a large dental company. It was said that the generosity of this dental company extended to the opening of its warehouses specifically for COC.

Guests that arrived for treatment received basic dental care. This mainly consisted of a basic examination, scale and polish, fillings, and if necessary, simple extractions. Most were very satisfied with this, although one guest did insist on having a dental implant while he was there.

\section{JOB SATISFACTION}

What made my experience most worthwhile, was the how most of the guests were genuinely appreciative of the service that was provided. Most understood that we had volunteered our skill and time and personally thanked us for it! I now truly understand the meaning of 'job satisfaction'.

I believe we all have a stereotypical image of the homeless, and certainly I had one prior to my experience with Crisis. For some of our guests the image may hold true, but for many others it does not. Certainly many of the guests were more appreciative, more intelligent, and definitely had a better sense of humour that many of the patients I see in practice. It probably goes to show, how one small wrong step in life can easily lead to a downward spiral of opportunities in our society today.

Simon Cheng Simon runs a referral implant practice in Battersea, London.

DOI: $10.1038 /$ bdj.2008.108 